\title{
IDENTIFICAÇÃO E ANÁLISE DE RISCOS EM LEVANTAMENTOS TOPOGRÁFICOS DE BARRAGENS DE USINAS HIDRELÉTRICAS: ESTUDO DE CASO NA UHE SALTO CAXIAS
}

Risk identifiation and analysis in topographic surveys of hidroelectric dams; a study case in UHE Salto Caxias

\author{
DANIEL CARVALHO GRANEMANN \\ Universidade Tecnológica Federal do Paraná \\ granemann@utfpr.edu.br
}

\begin{abstract}
RESUMO
Os levantamentos topográficos requerem cuidados e procedimentos de segurança a serem adotados pelos profissionais da área, pois dessa conduta depende o bom andamento das atividades, incorrendo em ganho de tempo, praticidade e minimização de riscos de acidentes de trabalho. No Brasil ainda é insípida a segurança em levantamentos topográficos, uma vez que as Normas Regulamentadoras (NRs) do Ministério do Trabalho, como a NR 18, são em grande parte aplicáveis a construção civil. Nestas normas não há abordagem alguma relacionada à Topografia, que por sua natureza também não se enquadra em trabalhos rurais, estando desprotegida dos amparos legais. Assim, este trabalho tem como objetivo a identificação e análise de riscos em levantamentos topográficos realizados na barragem da usina hidrelétrica Governador José Richa - Salto Caxias, no município de Capitão Leônidas Marques - PR. O trabalho propõe medidas de controle para os pontos mais críticos, através da Análise Preliminar de Riscos (APR), embasando a implantação futura de um Programa de Gerenciamento de Riscos, uma vez que possibilita a antecipação, identificação, avaliação e consequente controle dos riscos ambientais existentes ou que venham a existir no ambiente de trabalho.
\end{abstract}

Palavras-chave: Segurança; Levantamentos Topográficos; Análise de Riscos.

\section{ABSTRACT}

The topographic surveys require care and procedures by holding to be adopted by professionals, because this procedure will result in smooth a progress of activities, 
incurring time saving, convenience and minimize risks of accidents. In Brazil, the segurity of the topographic surveys is smallest, since the Regulatory Norms (NRs) from the State Department of Labor, as the NR 18, in the largely regarded to the civil construction. In these rules not there is no approach related to topography, which by their nature does not fit into the rural work, being unprotected from legal protections. This study aims at identifying an analysis of risks in topographic surveys made in hydroelectric dam Governador José Richa - Salto Caxias, in Capitão Leônidas Marques - PR. The work proposes control measures for the most critic points through the Preliminary Risk Analysis (PRA), leading to implantation of Program Management Risk as it enables anticipation the identification and consequent control of the risks that exists asl ready or will exist in the workplace.

Keywords: Security; Topographic Surveys; Risks Analysis.

\section{INTRODUÇÃO}

Tendo em vista que os levantamentos topográficos estão em constante movimentação e deslocamento, podem surgir situações de risco aos profissionais das equipes de trabalho, quer por falta de sinalização adequada no local de trabalho, ausência ou descumprimento de procedimentos, imperícia na operação dos instrumentos topográficos ou mesmo por falta de equipamentos de proteção coletiva e individual.

Dessa forma, considerando dados e informações obtidas em campanhas para o monitoramento da estrutura da barragem da Usina hidrelétrica Governador José Richa (Salto Caxias), no município de Capitão Leônidas Marques - PR, realizadas de 2002 a 2005, pretende-se readequar os procedimentos de segurança para estes trabalhos, através da identificação de riscos e a proposição de medidas de controle para o nivelamento geométrico da crista da barragem, monitoramento interno e externo desta.

O objetivo deste trabalho é identificar riscos e propor medidas de controle para levantamentos topográficos em barragens hidrelétricas, embasando a implantação de um Programa de Gerenciamento de Riscos (PGR), uma vez que possibilita a antecipação, identificação, avaliação e controle dos riscos ambientais existentes ou que venham a existir no ambiente de trabalho.

\section{GERENCIAMENTO DE RISCOS}

\subsection{Estrutura de um Programa de Gerenciamento de Riscos (PGR)}

A primeira etapa de um PGR está voltada à elaboração e implementação, com a antecipação dos riscos ambientais, denominada prevenção, que significa "chegar antes, antecipar”, originada do latim praevenire (PROTEÇÃO, 2009, p. 17). A antecipação envolve a análise de projeto de novas instalações, métodos ou processos de trabalho, ou de modificações das já existentes, objetivando a identificação de riscos potenciais e a introdução de medidas de proteção para sua 
redução ou eliminação.

A etapa seguinte refere-se ao reconhecimento dos riscos existentes nos locais de trabalho, estabelecendo prioridades, avaliando fatores de risco e exposição dos trabalhadores, acompanhamento das medidas de controle implementadas, monitorização da exposição aos fatores de riscos, registro e manutenção dos dados e avaliação periódica do programa.

Dessa forma, o PGR deve contemplar alguns aspectos, como por exemplo, riscos físicos, químicos e biológicos, ventilação, investigação e análise de acidentes do trabalho, ergonomia e organização do trabalho, riscos decorrentes do trabalho em espaços confinados, equipamento de proteção individual (EPI) e plano de emergência, onde está inserida a prestação de primeiros socorros.

\subsection{Riscos em Levantamentos Topográficos}

Conforme Glassey (2004), os levantamentos topográficos apresentam riscos de acidentes de trabalho constantes. Segundo o autor, os dados estatísticos indicam 20 acidentes fatais a cada 50.000 levantamentos realizados nos Estados Unidos, sendo uma parcela considerável devido aos acidentes de trajeto e trabalhos ao longo de rodovias (tem algum experimento realizado aqui no Brasil sobre o assunto. Se tiver comente, se não tiver, cite que não tem).

Quando se realizam trabalhos nessa área, alguns riscos estão presentes, tais como:

- Queda de pessoa de mesmo nível;

- Queda de materiais, equipamentos;

- Queda de nível diferente;

- Exposição à poeira;

- Impacto de objeto projetado;

- Queda de ferramentas e materiais;

- Corte.

Dentro dos programas de gestão de segurança estão contempladas algumas ferramentas de prevenção, como o Programa de Prevenção de Riscos Ambientais (PPRA), Programa de Controle Médico e Saúde Ocupacional (PCMSO) e APR.

O PPRA é parte integrante de um conjunto de medidas mais amplas, contidas nas demais Normas Regulamentadoras (NR 09, 1978), articulando-se principalmente com a NR 07 - Programa de Controle Médico de Saúde Ocupacional (PCMSO) e de Prevenção de Perdas Auditivas (PPPA). Seu principal objetivo é fazer da prevenção de acidentes e doenças ocupacionais uma forma de eliminar ou minimizar os riscos para os trabalhadores, melhorando o desempenho dos negócios e auxiliando as organizações em geral, estabelecendo uma imagem responsável da empresa no mercado (SESI, 2009).

Conforme o autor, para o desenvolvimento do PPRA deve ser realizado uma abordagem com a finalidade de aplicar técnicas de higiene e segurança ocupacional com recursos disponíveis, atribuindo responsabilidades e integrando o Serviço de 
Segurança e Saúde do Trabalhado em toda organização, envolvendo e comprometendo os trabalhadores através de documentações e treinamentos em serviços especializados.

Dentre as vantagens do PPRA, destacam-se:

- Prevenção de acidentes de trabalho;

- Redução de perdas de material e de pessoal;

- Otimização dos custos;

- Redução dos gastos com saúde;

- Aumento da qualidade, produtividade e competitividade.

A elaboração e implementação deste programa é única e total responsabilidade do empregador, devendo zelar pela sua eficácia, sendo sua profundidade e abrangência dependentes das características dos riscos ambientais e necessidades de controle.

Os riscos ambientais são entendidos como tudo o que tem potencial para gerar acidentes no trabalho, em função de sua natureza, concentração, intensidade e tempo de exposição, dividindo-se em agentes físicos, químicos, biológicos e ergonômicos, sendo que em levantamentos topográficos em áreas de barragens, os agentes que estão mais presentes são os físicos e os ergonômicos.

Os Agentes Físicos são representados pelas condições físicas no ambiente de trabalho, como por exemplo, vibração, ruído, calor, frio, podendo causar danos à saúde.

Agentes Químicos são encontrados em forma gasosa, líquida, sólida e pastosa. A poeira é um exemplo de partícula sólida, que por ação do vento, e dependendo do tamanho da partícula, pode causar pneumoconiose - doença respiratória provocada pela inalação de partículas suspensas no ar por períodos prolongados - tumores pulmonares, alergias e irritações nas vias respiratórias.

Agentes Biológicos são microorganismos patógenos presentes no ambiente de trabalho, como bactérias, fungos, vírus, bacilos, parasitas, capazes de produzir doenças, deterioração de alimentos, entre outros, e que apresentam facilidade de reprodução, além de contarem com diversos processos de transmissão.

Agentes Ergonômicos são o conjunto de conhecimentos sobre o homem e o ambiente de trabalho, fundamentais ao planejamento de tarefas, postos e ambientes laborais, ferramentas e máquinas, a fim de que sejam utilizados com o máximo de conforto, segurança e eficiência. Dentre os casos mais comuns de problemas ergonômicos têm-se o esforço físico intenso, levantamento e transporte manual de peso, monotonia e repetividade.

\section{AVALIAÇÃO DE RISCOS}

Conforme Cardella (1999), o risco associado a um evento é resultado da sua frequência e consequência. A frequência pode ser entendida como o número de ocorrências na unidade de tempo, tendo por unidades a ocorrência/ano ou ocorrência/hora. 
De acordo com o autor, nas avaliações de frequências podem ocorrer multiplicações da frequência com que um evento ocorre pela probabilidade deste ocorrer, resultando em um quadro de avaliação de frequência (Quadro 1).

Quadro 1 - Avaliação de Frequência. Fonte: Adaptado de Cardella (1999).

\begin{tabular}{|c|l|l|}
\hline Categoria & \multicolumn{1}{|c|}{ Probabilidade } & \multicolumn{1}{c|}{ Característica } \\
\hline 0 & $\begin{array}{l}\text { Extremamente } \\
\text { baixa }\end{array}$ & $\begin{array}{l}\text { Possível teoricamente, mas altamente } \\
\text { improvável. }\end{array}$ \\
\hline 1 & Muito baixa & $\begin{array}{l}\text { Pode ocorrer em situações muito especiais; } \\
\text { sua ocorrência não é esperada. }\end{array}$ \\
\hline 2 & Baixa & Pode ocorrer raramente \\
\hline 3 & Média & Pode ocorrer com relativa facilidade \\
\hline 4 & Alta & Pode ocorrer com muita facilidade \\
\hline
\end{tabular}

Na avaliação das consequências o objetivo é avaliar a área de abrangência do agente agressivo, calculando-se a capacidade agressiva em cada ponto. Conforme o autor, deve-se escolher o evento perigoso de nível adequado para enquadrar a conseqüência do evento (Quadro 2).

Quadro 2 - Avaliação de Consequência. Fonte: Adaptado de Cardella (1999).

\begin{tabular}{|c|l|l|}
\hline Categoria & Probabilidade & \multicolumn{1}{|c|}{ Característica das Lesões } \\
\hline 0 & Desprezível & Incômodos passageiros \\
\hline 1 & Muito leve & Recuperação muito rápida \\
\hline 2 & Leve & $\begin{array}{l}\text { Provocam sofrimentos passageiros, não } \\
\text { incapacitando para o trabalho }\end{array}$ \\
\hline 3 & Média baixa & $\begin{array}{l}\text { Não resultam em danos permanentes; provocam } \\
\text { incapacidade temporária por períodos menores } \\
\text { que uma semana }\end{array}$ \\
\hline 5 & Média & $\begin{array}{l}\text { Não resultam em danos permanentes; provocam } \\
\text { incapacidade temporária por períodos maiores } \\
\text { que uma semana }\end{array}$ \\
\hline 6 & Média Alta & $\begin{array}{l}\text { Resultam em perda permanente de funções; não } \\
\text { afetam acentuadamente a vida normal }\end{array}$ \\
\hline 7 & Grave & $\begin{array}{l}\text { Incapacitam para o trabalho ou outras } \\
\text { atividades }\end{array}$ \\
\hline 8 & Muito grave & Morte \\
\hline 9 & grave & Algumas mortes \\
\hline
\end{tabular}

Assim, para a análise qualitativa dos riscos, realiza-se a combinação do

Bol. Ciênc. Geod., sec. Comunicações/Trab. Tecnicos Curitiba, v. 16, no 4, p.609-622, out-dez, 2010. 
Quadro 1 e Quadro 2, obtendo-se as categorias de riscos (QUADRO 3).

Quadro 3 - Categorias de Riscos. Fonte: Adaptado de Cardella (1999).

\begin{tabular}{|c|r|r|r|r|r|r|r|r|r|r|r|r|}
\hline \multirow{2}{*}{\begin{tabular}{c} 
Categoria $\begin{array}{c}\text { Categoria de consequência } \\
\text { frequênci } \\
\text { a }\end{array}$ \\
\cline { 2 - 12 }
\end{tabular}} & \multicolumn{10}{|c|}{ Categoria de risco } \\
\hline 0 & 0 & 1 & 2 & 3 & 4 & 5 & 6 & 7 & 8 & 9 \\
\hline 1 & 0 & 0 & 1 & 1 & 2 & 2 & 2 & 3 & 3 & 3 \\
\hline 2 & 2 & 2 & 2 & 3 & 3 & 4 & 4 & 5 & 5 & 5 \\
\hline 3 & 2 & 3 & 4 & 5 & 5 & 5 & 6 & 7 & 8 & 8 \\
\hline 4 & 3 & 4 & 4 & 5 & 6 & 6 & 7 & 8 & 9 & 9 \\
\hline
\end{tabular}

Dessa forma, é possível avaliar qualitativamente os riscos inerentes às atividades realizadas, inferindo sobre as medidas de controle a serem adotadas, visando a minimização das consequências (Quadro 4).

Quadro 4 - Avaliação Qualitativa de Riscos. Fonte: Adaptado de Cardella (1999).

\begin{tabular}{|c|c|c|}
\hline Categoria & Qualitativo & Controle \\
\hline 0 & Extremamente baixo & Basta ser identificado \\
\hline 1 & Muito baixo & Verificação das possibilidades de ocorrência \\
\hline 2 & Baixo & $\begin{array}{l}\text { Requer ações integrantes de um programa tipo } \\
\text { sinalização - ordem - limpeza (SOL), e boas } \\
\text { práticas de trabalho (BPT) }\end{array}$ \\
\hline 3 & Médio baixo & Requer ações de SOL e BPT \\
\hline 4 & Médio tolerado & Requer ações de melhoria contínua \\
\hline 5 & Médio não tolerado & Programa específico de controle de riscos \\
\hline 6 & Elevado & Ações urgentes \\
\hline 7 & Médio Elevado & $\begin{array}{llll}\begin{array}{l}\text { Intervenção } \\
\text { atividades que geram o risco }\end{array} & & \text { cessação } & \text { das } \\
\end{array}$ \\
\hline 8 & $\begin{array}{l}\text { Individual } \\
\text { extremamente } \\
\text { elevado }\end{array}$ & \multirow{2}{*}{$\begin{array}{l}\text { Intervenção imediata com cessação das } \\
\text { atividades que geram o risco }\end{array}$} \\
\hline 9 & $\begin{array}{l}\text { Social } \\
\text { extremamente } \\
\text { elevado }\end{array}$ & \\
\hline
\end{tabular}

De acordo com a Análise Preliminar de Riscos (APR) realizada, os riscos podem ser classificados conforme o Quadro 5. 
Quadro 5 - Categorias de Riscos. Fonte: Adaptado de Souza (2009, p. 21).

\begin{tabular}{|c|l|}
\hline Categoria & \multicolumn{1}{|c|}{ Falha } \\
\hline 1. Desprezível & $\begin{array}{l}\text { Não resultará em degradação maior do sistema, nem } \\
\text { produzir danos funcionais ou lesões, ou mesmo contribuir } \\
\text { com um risco ao sistema }\end{array}$ \\
\hline 2. Limítrofe & $\begin{array}{l}\text { Degradação do sistema em uma certa extensão, porém sem } \\
\text { causar danos maiores ou lesões }\end{array}$ \\
\hline 3. Crítica & $\begin{array}{l}\text { Degradação do sistema causando lesões, danos } \\
\text { substanciais, resultando em risco inaceitável, necessitando } \\
\text { ações corretivas imediatas }\end{array}$ \\
\hline 4. Catastrófica & $\begin{array}{l}\text { Degradação severa do sistema, resultando em perda total, } \\
\text { lesões ou morte }\end{array}$ \\
\hline
\end{tabular}

\section{MÉTODO DE PESQUISA}

\subsection{Local de Trabalho}

A Usina Hidrelétrica Governador José Richa - Salto Caxias - está situada no Rio Iguaçu, no município de Capitão Leônidas Marques. Esta faz parte do complexo de usinas construídas no Rio Iguaçu.

\subsection{Obtenção dos Dados}

O trabalho consistiu em acompanhar os levantamentos geodésicos , vinculados ao projeto de pesquisa "Automação da instrumentação de Auscultação Geodésica de controle e segurança da barragem de Salto Caxias, , observando e descrevendo todas as atividades realizadas pelos membros da equipe do projeto envolvidos.

Em um primeiro momento foram identificados os riscos destas atividades, para em seguida serem analisados e classificados, conforme Cardella (1999), exposto no item 3.

Na sequência realizou-se a APR para os pontos críticos dos levantamentos, identificados pela classificação anterior, determinando-se os riscos principais, iniciais e contribuintes, as formas de eliminação e controle destes riscos.

\section{ANÁLISE DOS POSTOS DE TRABALHO}

\subsection{Nivelamento da Crista da Barragem}

O nivelamento geométrico na crista da barragem (Figura 3) visa a determinação do deslocamentos verticais (recalque) dos blocos que compõem a sua estrutura, através de campanhas periódicas. 
Figura 3 - Nivelamento geométrico - crista da barragem.

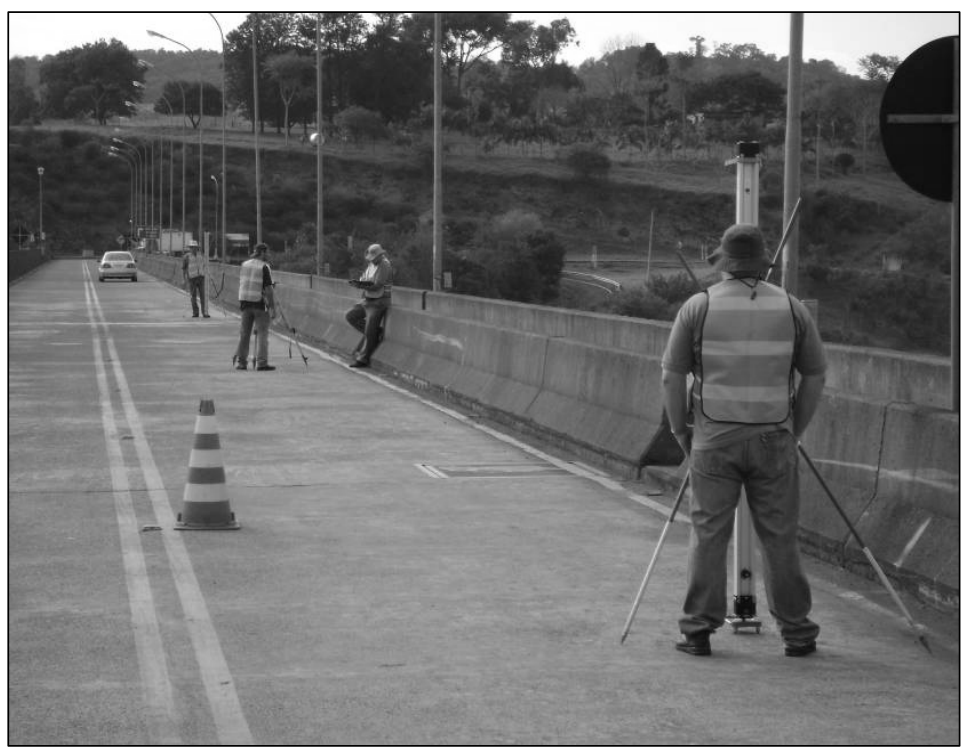

Fonte: O Autor

Este é realizado sob condições climáticas e atmosféricas variadas - calor, frio, chuva - não havendo intervalo para descanso. O trabalho tem duração média de 5 horas, havendo a passagem constante de veículos no local, além de animais peçonhentos como aranhas e lacraias.

\subsection{Monitoramento da Rede Externa}

Nestes trabalhos, a equipe que realiza os levantamentos ,ficam expostos a temperaturas extremas durante o dia, em virtude do calor, frio, chuva, entre outros. Durante toda a jornada o operador do instrumento de medida (estação total) permanece em pé, conforme ilustra a Figura 4 uniformizar, em alguns casos você coloca FIGURA entre parênteses e em outro não, realizando observações de direções e distâncias aos vértices da rede. Os postos de trabalho ficam próximos à matas e matagais, e a presença de animais peçonhentos é constante. Além disso, o desnível entre o ponto de observação e a pista de rolamento, além do guardacorpo, constitui um risco de acidente, agravado pelo ofuscamento da visão em observações noturnas. 
Figura 4 - Posto de trabalho P1 - rede externa.

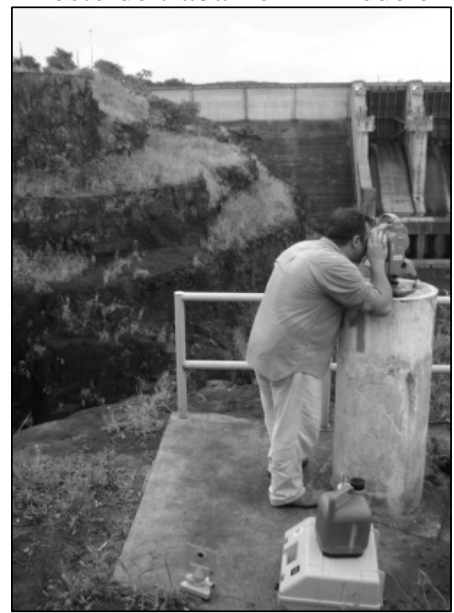

Fonte: O Autor

\subsection{Monitoramento da Rede Interna}

Este trabalho é realizado em períodos diuturnos, e os operadores permanecem em pé durante as jornadas, conforme ilustram a Figura 5, operando e transportando instrumentos, equipamentos e acessórios, havendo o intervalo de uma hora para o almoço. Os postos de trabalho na entrada e saída da galeria de inspeção estão sujeitos a riscos de queda da própria altura, entorce e animais peçonhentos.

Figura 5 - Postos de trabalho - rede interna de monitoramento.

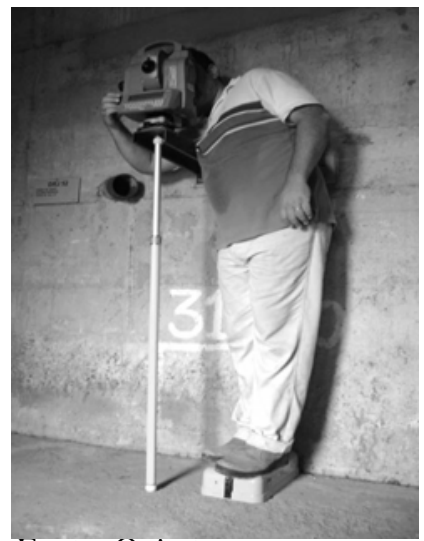

Fonte: O Autor

Bol. Ciênc. Geod., sec. Comunicações/Trab. Tecnicos Curitiba, v. 16, nº 4, p.609-622, out-dez, 2010. 


\section{DISCUSSÕES E CONCLUSÃO}

\section{1 Avaliação de Riscos}

Em virtude do maior número de reclamações de posturas inadequadas, excesso e insuficiência de iluminação, ruídos e temperaturas extremas nos monitoramentos interno e externo da barragem, analisaram-se as freqüências com que ocorrem os problemas, e as consequências dos riscos destas atividades, sendo classificados de acordo com o exposto no Quadro 1 e Quadro 2, respectivamente. Os enquadramentos são apresentados na Tabela 1não encontrei a tabela 1.

Tabela 1 - Riscos - Frequências e Conseqüências.

\begin{tabular}{l|c|c}
\hline \multicolumn{1}{c|}{ Atividades } & \multirow{2}{*}{ Freq. } & Cons. \\
\cline { 1 - 2 } $\begin{array}{l}\text { Monitoramento Externo } \\
\text { (postura, iluminação, ruídos, temp. } \\
\text { extrema) }\end{array}$ & 3 & 6 \\
\hline Pilar P1 & 3 & 6 \\
\hline Pilar P2 & 2 & 3 \\
\hline Pilar P3 & 2 & 7 \\
\hline Pilar P6 & 3 & 2 \\
\hline $\begin{array}{l}\text { Monitoramento Interno } \\
\text { (postura, iluminação, ruídos, temp. } \\
\text { extrema, fadiga) }\end{array}$ & & \\
\hline
\end{tabular}

Considerando-se a Tabela 1, realizou-se a avaliação qualitativa dos riscos das atividades (Tabela 2), conforme proposto por Cardella (1999).

Tabela 2 - Avaliação Qualitativa de Riscos.

\begin{tabular}{l|c|c|l}
\hline \multicolumn{1}{c|}{ Atividades } & \multirow{2}{*}{ Categoria } & $\begin{array}{c}\text { Qualitativ } \\
\text { Monitoramento }\end{array}$ & Controle \\
$\begin{array}{l}\text { Externo (postura, } \\
\text { iluminação, ruídos } \\
\text { e temp. extrema) }\end{array}$ & & & \\
\hline Pilar P1 & 6 & Elevado & $\begin{array}{l}\text { O que são Ações } \\
\text { Urgentes? }\end{array}$
\end{tabular}


Continuação Tabela 2...

\begin{tabular}{l|c|l|l}
\hline Pilar P2 & 6 & Elevado & $\begin{array}{l}\text { Ações } \\
\text { Urgentes }\end{array}$ \\
\hline Pilar P3 & 3 & $\begin{array}{l}\text { Médio } \\
\text { Baixo }\end{array}$ & $\begin{array}{l}\text { Requer ações } \\
\text { de SOL eBPT }\end{array}$ \\
\hline Pilar P6 & 5 & $\begin{array}{l}\text { Médio não } \\
\text { tolerado }\end{array}$ & $\begin{array}{l}\text { Programa } \\
\text { específico de } \\
\text { controle de } \\
\text { riscos }\end{array}$ \\
\hline $\begin{array}{l}\text { Monitoramento } \\
\text { Interno (postura, } \\
\text { iluminação, ruídos, } \\
\text { temp. extrema, fadiga) }\end{array}$ & 4 & $\begin{array}{l}\text { Médio } \\
\text { tolerado }\end{array}$ & $\begin{array}{l}\text { Requer ações } \\
\text { de melhoria } \\
\text { contínua }\end{array}$ \\
\hline
\end{tabular}

$\mathrm{Na}$ sequência foram elaboradas as APR para os levantamentos que apresentaram o maior grau de risco (Quadro 7).

Quadro 7 - Análise Preliminar de Riscos: Levantamentos Topográficos na UHE ANÁLISE PRELIMINAR DE RISCOS

Local de Trabalho: Rede Geodésica de Monitoramento Externo - UHE Salto

Caxias

Data: 09/02/2009

Responsável pela análise: Daniel C. Granemann

\begin{tabular}{|c|c|c|c|c|c|}
\hline \multirow[t]{2}{*}{ Pto } & Risco & \multirow{2}{*}{ Causa } & \multirow{2}{*}{ Efeito } & \multirow{2}{*}{$\begin{array}{l}\text { Categoria } \\
\text { de Risco }\end{array}$} & \multirow{2}{*}{ Tratamento } \\
\hline & Biológico: & & & & \\
\hline P1, & $\begin{array}{l}\text { Picadas } \\
\text { de aranhas, } \\
\text { cobras, } \\
\text { lacraias, } \\
\text { etc. }\end{array}$ & $\begin{array}{l}\text { Locais de } \\
\text { rabalho sem } \\
\text { aceiro }\end{array}$ & $\begin{array}{l}\text { Asfixia, } \\
\text { câimbras, } \\
\text { inchaço, } \\
\text { náuseas, morte }\end{array}$ & Catastrófica & $\begin{array}{l}\text { Uso de } \\
\text { caneleiras até a } \\
\text { altura do joelho; } \\
\text { Utilização } \\
\text { de luvas para a } \\
\text { limpeza dos } \\
\text { locais de } \\
\text { trabalho; botas } \\
\text { de segurança, } \\
\text { inspeção local } \\
\text { antes do início } \\
\text { das atividades }\end{array}$ \\
\hline & $\begin{array}{l}\text { Picadas de } \\
\text { mosquitos } \\
\text { e } \\
\text { pernilongos }\end{array}$ & $\begin{array}{l}\text { Locais de } \\
\text { rabalho com } \\
\text { acúmulo de } \\
\text { água }\end{array}$ & $\begin{array}{l}\text { Inchaço, } \\
\text { alergia, } \\
\text { coceira }\end{array}$ & Crítica & \begin{tabular}{l}
\multicolumn{1}{c}{ Uso de } \\
repelentes; \\
camisas manga \\
longa, calça \\
comprida e botas \\
de segurança
\end{tabular} \\
\hline
\end{tabular}

Bol. Ciênc. Geod., sec. Comunicações/Trab. Tecnicos Curitiba, v. 16, no 4, p.609-622, out-dez, 2010. 


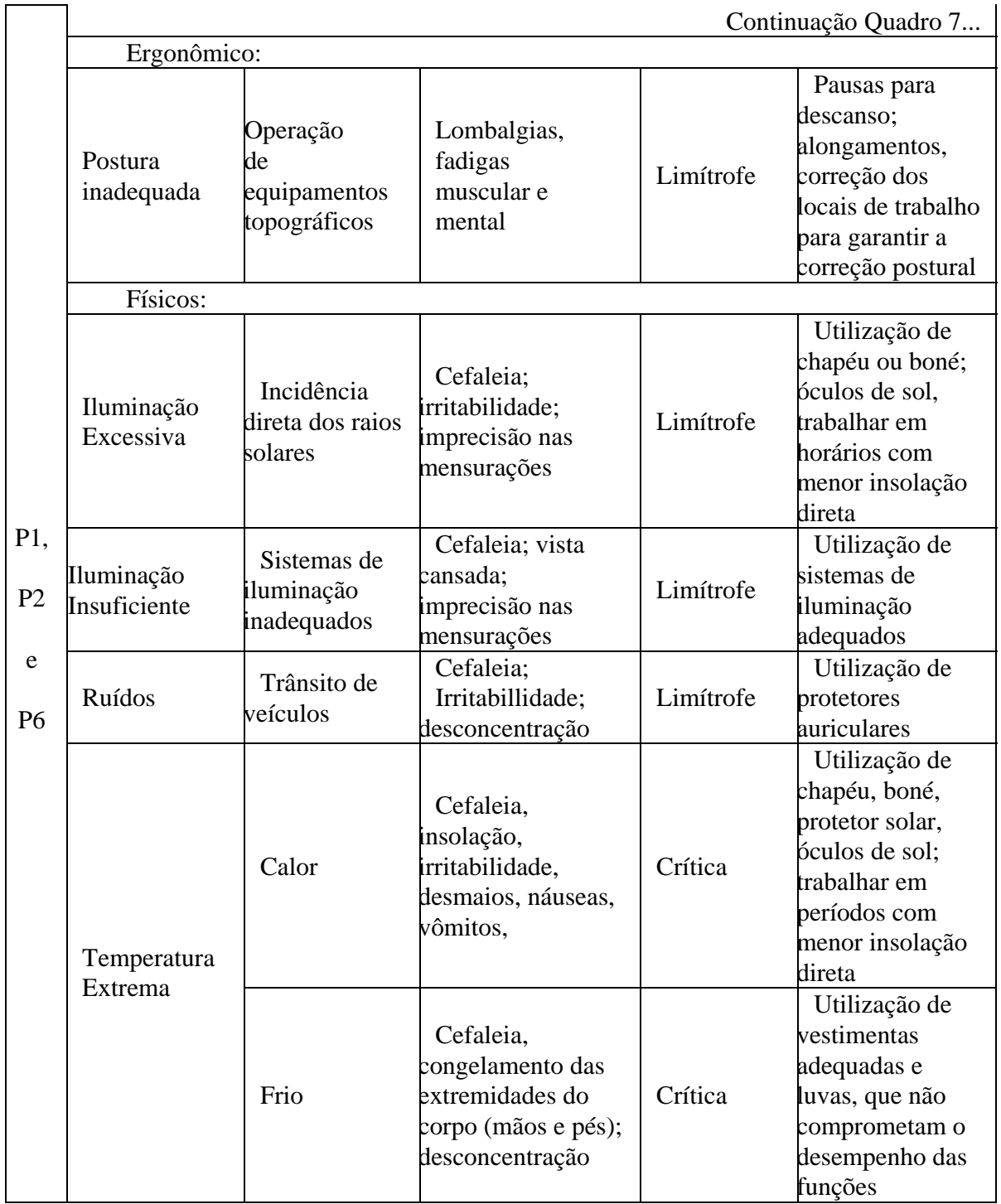

Considerando-se a avaliação qualitativa e a análise preliminar de riscos, percebe-se a importância de intervir imediatamente em alguns postos de trabalho, uma vez que apresentam maior grau de risco aos trabalhadores.

No monitoramento externo da barragem, a partir do pilar P1, não se apresentam EPC adequados, conforme visualizado na figura 15, em que o guarda- 
corpo utilizado não oferece a proteção adequada. Esta atividade atualmente é realizada no período noturno, para minimizar efeitos atmosféricos, tais como reverberação e refração, visando observar direções e distâncias com qualidade. Em virtude do horário do início da atividade, o local torna-se mal iluminado, aumentando os riscos de quedas e escoriações.

A limpeza dos acessos ao pilar $\mathrm{P} 1$, a readequação do guarda-corpo, através de um projeto que ofereça segurança para a equipe no desempenho de suas funções, e a utilização de cinto travaqueda, tipo paraquedista, minimizariam os riscos da atividade. Ressalta-se que para os pilares P2 e P6 medidas idênticas são necessárias e igualmente válidas.

A região do corpo mais afetada, de acordo com informações dos próprios membros da equipe , é a região torácica, seguida da lombar. Há queixas de dores nas articulações dos membros superiores e inferiores, ombros e joelhos, respectivamente, por ocasião dos trabalhos realizados em pé. Neste sentido, devem ser adotadas pausas para descansos e alongamentos, proporcionando bem estar e relaxamento. A análise ergonômica do posto de trabalho aliada à fisioterapia também é importante, uma vez que o investimento em prevenção e saúde implica diretamente no aumento da produtividade, eficiência e motivação. Contudo, o trabalhador tem o dever de participar do aprendizado e aplicação das estratégias para a redução dos riscos. Não obstante, a empresa deve investigar e reconhecer os sintomas de risco, pois respeitar os limites individuais significa prevenir lesões na coluna, os quais podem afastar temporária ou definitivamente o trabalhador de suas atividades.

Dos riscos físicos elencados na APR, o calor e o frio são os maiores causadores de irritabilidade e cefaleia, influenciando diretamente na execução das tarefas. As dores de cabeça afetam diretamente a visão e a audição, sensibilizandoos, desconcentrando o trabalhador, tornando-o susceptível a acidentes. Como os levantamentos topográficos na barragem são realizados em horários próximos ao meiodia, há o aumento da temperatura ambiente e interna do corpo, desencadeando reações químicas e térmicas que podem ocasionar desmaios, náuseas e vômitos.

Visando a minimização destes efeitos, os quais ocorrem mais intensamente no verão, deve-se realizar as atividades até no máximo 11 horas, no período matutino, e após às 15 horas, no período vespertino. Além disso, a utilização de vestimentas adequadas e compatíveis para o desempenho das funções, bem como protetor solar, proteção para a cabeça e os olhos, como chapéus e óculos de sol, respectivamente, melhoram as condições de trabalho, proporcionando bem estar aos colaboradores.

\section{REFERÊNCIAS BIBLIOGRÁFICAS}

CARDELLA, B. Segurança no Trabalho e Prevenção de Acidentes: uma abordagem holística: segurança integrada à missão organizacional com produtividade, qualidade, prevenção ambiental e desenvolvimento de pessoas. São Paulo: Atlas, 1999. 
CPNSP - Comissão Tripartite Permanente de Negociação do Setor Elétrico no Estado de São Paulo. Técnicas de Análise de Risco. Disponível em: http://www.fundacentro.gov.br. Acesso em 17/08/09.

GEMAEL, C., FAGGION, P.L. Subsidência na Região de Grandes Barragens. Revista Brasileira de Geofísica, vol.14, n.3, pp.281-285. 1996.

GLASSEY, R. W. Developing a Safety Plan - Survey Safety. The American Surveyor. December, 2004. Disponível em: http://www.theamericansurveyor.com Acesso em 28/07/09.

GRANEMANN, Daniel C. Estabelecimento de uma Rede Geodésica para o Monitoramento de Estruturas: Estudo de Caso na Usina Hidrelétrica Salto Caxias. 2005. 114 p. Dissertação. Universidade Federal do Paraná, Curitiba, 2005.

MINISTÉRIO DO TRABALHO E PREVIDÊNCIA SOCIAL. Norma Regulamentadora 9: Programa de Prevenção de Riscos Ambientais. 1978.

PROTEÇÃO - Revista Mensal de Saúde e Segurança do Trabalho. Novo Hamburgo. Proteção Publicações, Edição 208. Abril 2009.

SESI - Serviço Social da Indústria. Programa de Prevenção de Riscos Ambientais.

Disponível em:

http://www.sesipr.org.br/saude/FreeComponent85content294.shtml. Acesso em 10/08/2009.

SOUZA, J. M. Gerência de Riscos - Parte II. Apostila. IV Turma do Curso de Especialização em Engenharia de Segurança do Trabalho. Universidade Tecnológica Federal do Paraná, Pato Branco. 2009.

(Recebido em julho de 2010. Aceito em dezembro de 2010.) 